\title{
Comparison of SF-36 and WHOQOL-100 in patients with stroke
}

\author{
Unalan Demet, Soyuer Ferhan, Ozturk Ahmet ${ }^{1}$, Mistik Selcuk ${ }^{2}$ \\ Erciyes University Halil Bayraktar Health Services Vocational College, TR-38039, Kayseri, Turkey, ${ }^{1}$ Erciyes University School of Medicine, \\ Department of Biostatistics, 38039-Kayseri / Turkey, ${ }^{2}$ Erciyes University School of Medicine, Department of Family Medicine, 38039-Kayseri/Turkey
}

\begin{abstract}
Background and Aims: Two widely used evaluation tools for the quality of life are the 36-item Short-Form Health Survey (SF-36) and World Health Organization Quality of Life Assessment (100-item version) (WHOQOL-100), however, these tools have not been compared for patients with stroke to date. The specific objectives of this study were: 1) to study the effect of stroke on quality of life (QOL) as measured by the SF-36 and by the WHOQOL-100, and 2) to compare these two instruments. Settings and Design: Seventy patients who were admitted to the neurology clinic six months after stroke were included in this study. Materials and Methods: As a data-collecting device, the SF-36 and WHOQOL-100 scales were used. An additional questionnaire was administered to obtain demographic data. Statistical Analysis: Pearson correlation analysis was performed and Blant-Altman Plots were used. Psychometric analysis was performed. Results: In stroke, the most flustered domains of quality of life were vitality and general health perception fields in the SF36 and in the WHOQL-100, independence level field, overall QOL and general health perceptions. While there was a fair degree of relationship $(r=0.25-0.50)$ between general health perceptions, physical, social and mental fields that were similar fields of scales, a fair and moderate to good relationship was found between different fields. Limits of agreement in similar domains of the two instruments were very large. In all four demonstrated Bland-Altman plots, there was agreement of the scales in the measurements of similar fields of quality of life. Conclusion: This study demonstrated that both the SF36 and WHOQOL-100 quality of life scales are useful in the practical evaluation of patients with stroke.
\end{abstract}

Key words: Agreement, instruments, quality of life, stroke

\section{Introduction}

Stroke is a major public health problem, which causes high morbidity and mortality in many countries. ${ }^{[1]}$ Stroke is the most common neurological problem in the world ${ }^{[2]}$ and has an effect on the psychological and physical favor of patients and their families. ${ }^{[1,3]}$ In Turkey, as is the case all over the world, stroke is the third most common cause of death following cancer and heard attack. Furthermore, it is the most common disease causing disability.

Medical complications after stroke are the worsening of patients' quality of life, which represents problems to be solved. Stroke is an injury that results in serious physical and cognitive impairment over a long period, which negatively effects the survivor's quality of life (QOL) $)^{[4]}$ Post-stroke life satisfaction and life quality related to stroke are health problems that do not attract sufficient attention in many countries, including Turkey.

The Medical Outcomes Study 36-item Short-Form Health Survey (SF-36) is a widely used, generic, patientreport, health status measure. It is recommended for use in health policy evaluations, general population surveys, clinical research, and clinical practice. In neurology, the SF-36 has been used in stroke patients in many studies. ${ }^{[5]}$ Among the studies using the SF-36 in patients with stroke, several have examined some of its psychometric properties. These studies report adequate internal consistency reliability ${ }^{[6]}$ and support the convergent and discriminant construct validity ${ }^{[7]}$ and group differences validity $^{[6]}$ of the SF-36 in stroke patients. Floor and ceiling effects have been demonstrated by some ${ }^{[7,8]}$ but not others. ${ }^{[6]}$ The World Health Organization Quality of Life Assessment (100-item version) (WHOQOL100) has four domains: physical health, psychological health, social relationships and environment. It also includes one facet covering overall QOL and general health. These two scales have similar fields: physical, social, mental fields, and general health perception, and different subgroups: independence level, environment, beliefs, physical role limitations and emotional role limitations. The WHOQOL-100 has proved to be a reliable and valid instrument for assessing the QOL of patients with chronic diseases (including hypertension, schizophrenia, stroke, end-stage renal disease, head and 
neck cancer, and breast cancer) and their caregivers in China. ${ }^{[9]}$ There is no study in the literature comparing the use of these two scales in stroke patients.

The specific objectives of this study were to: 1 ) study the effect of stroke on general HRQoL as measured by the SF-36 and by the WHOQOL-100, and 2) compare these two scales.

\section{Materials and Methods}

\section{Patients}

Patients admitted to the Neurology Outpatient Clinic from March 2004 to March 2005 were included in the study. Of the 90 stroke patients who fulfilled the inclusion criteria during this period, $70(77 \%)$ patients agreed to participate in the study. The patients were asked to visit the outpatient clinic at an appointed date. All of the patients gave informed consent. Erciyes University Ethics Committee approved this study.

The inclusion criteria were: 1) Cerebral infarction or hemorrhage demonstrated by computerized tomography (CT) or magnetic resonance imaging (MRI), 2) Having had a stroke six months or more previously, 3) Having had a stroke for the first time, and 4) Accepting to be interviewed at the appointed date. Patients with communication problems were excluded from the study.

An additional questionnaire was administered to obtain the patients' demographic data. These data included age, gender, marital status, education level, occupation, income, health insurance, and the people with whom the patient lived.

\section{Instruments}

The SF-36 and WHOQOL-100 quality of life instruments were used in this study.

\section{SF-36 Quality of life scale}

The SF-36 is a multipurpose, short-form health survey with only 36 questions. It yields an eight-scale profile of scores as well as physical and mental summary measures. It is a generic measure, as opposed to one that targets a specific age, disease, or treatment group. ${ }^{[10]}$ The SF-36 Health Survey contains 36 items that are scored out of eight scales: physical functioning (PF), role limitations due to physical health problems (RP), bodily pain (BP), general health (GH), vitality (VT), social functioning (SF), role limitations due to emotional problems (RE) and mental health (MH). It also includes a single item that provides an indication of perceived change in health. For each scale, a score ranging from 0 (worst measured health) to 100 (best measured health) was calculated. ${ }^{[11]}$ Scores on the eight SF-36 scales were further aggregated to produce physical and mental component summary (PCS and MCS) measurements of health status. The PCS and MCS were also scored using norm-based methods. ${ }^{[12]}$ The SF-36 is suitable for self-administration, computerized administration, or administration by a trained interviewer in person or by telephone, to persons aged 14 years and older. ${ }^{[10]}$ The reliability and the validity of the SF-36 scale for the Turkish population were performed by Pinar. ${ }^{[13]}$

2. WHOQOL-100 Quality of life scale

The WHOQOL-100 is a generic measure designed for use with a wide spectrum of psychological and physical disorders. ${ }^{[14,15]}$ It is a multidimensional, multilingual profile for subjective assessment. During development, focus groups of patients, health professionals and well people proposed items that were selected and attached to a five-point interval, likert response scale. The 100 items are organized in 25 facets, subsumed within six domains. The WHOQOL-100 has six domains: physical, psychogical, social relationships, environment, independence, and spiritual. It also includes one facet covering overall QOL and general health. High scores (recoded for negatively framed items) indicate good QOL. Respondents judge their quality of life in the previous two weeks. ${ }^{[16]}$

\section{Statistical Analysis}

Data were expressed as mean \pm standard deviation $(\bar{X} \pm S D)$ or median with minimum-maximum values. Reliability tests included internal consistency, determined by Cronbach's alpha. The prevalence of the lowest (floor effect) and highest (ceiling effect) possible QOL score in the SF-36 and WHOQOL-100 was also calculated. Pearson's correlations were used to determine the level of agreement between two comparable subscales of the two instruments, while $\mathrm{R}^{2}$ was used to determine the percentage of expressed variance. As a general guideline, correlations from 0.00 to 0.25 indicate little or no relationship, from 0.25 to 0.50 a fair degree of relationship, from 0.50 to 0.75 a moderate to good relationship, and above 0.75 a good to excellent relationship. Agreement of similar domains between the SF-36 and WHOQOL-100 was analyzed by using Bland-Altman plots. The sum of twice the SDs was used to estimate the widest likely 95\% confidence interval for the SF-36 and WHOQOL100 comparison. All analyses were performed using SPSS for Windows, version 13.0. $P<0.05$ values were considered significant. ${ }^{[17]}$

\section{Results}

\section{Patient characteristics}

Seventy patients with stroke were included in the study. There were 27 female (38.6\%) and 43 male (61.4\%) patients in the study group. The mean \pm SD age was $60.16 \pm 11.30$ years, and the age range was 23-83 years. Of the patients, $85.7 \%$ were married, $67.1 \%$ were 
primary school graduates or less educated, $40.0 \%$ were retired, $94.3 \%$ had health insurance, $67.1 \%$ lived in the city center, $95.7 \%$ lived with other family members, and the salary range was $32-2112$ USD with a median of 352 USD [Table 1].

Fifty-one per cent of the patients had comorbid diseases, and the most common diseases were hypertension (45.7\%) and diabetes mellitus (14.3\%). Eighty per cent of the patients fulfilling the inclusion criteria were included in the study.

\section{WHOQOL-100 Quality of life scale}

The evaluation of patients' QOL with the WHOQOL100 revealed that independence level, overall QOL and general health perceptions were the most deteriorated fields of QOL [Table 2]. The least affected subgroup was self-respect, and the most affected subgroups were dependence on drugs and therapy, pain and discomfort, liveliness and fatigue, and social support.

\section{SF-36 Quality of life scale}

The evaluation of patients' QOL with SF-36 revealed that general health perceptions and vitality dimensions were the most common fields that deteriorated the QOL [Table 2].

The analysis of subscales for both test instruments is shown in Table 2 . The prevalence of patients with best possible scores, referred to as ceiling effect, was higher for the SF-36 scale (range, 1.4-37.1\%) than for the domains of the WHOQOL-100 scale (range, 1.4$2.9 \%)$. The prevalence of the worst possible scores,

\begin{tabular}{|c|c|c|}
\hline & & \\
\hline $\begin{array}{l}\text { Variables } \\
\text { Sex }\end{array}$ & $\mathbf{n}$ & $\%$ \\
\hline Male & 43 & 61.4 \\
\hline Female & 27 & 38.6 \\
\hline Age $(\bar{X} \pm S D)(\min -\max )$ & $60.16 \pm 11.30$ & $(23-83)$ \\
\hline \multicolumn{3}{|l|}{ Marital Status } \\
\hline Married & 60 & 85.7 \\
\hline Divorced-Widowed & 10 & 14.3 \\
\hline \multicolumn{3}{|l|}{ Education } \\
\hline Primary school graduates or less & 47 & 67.1 \\
\hline Middle school and over & 23 & 32.9 \\
\hline \multicolumn{3}{|l|}{ Occupation } \\
\hline Retired & 28 & 40 \\
\hline Housewife & 27 & 38.6 \\
\hline Other & 15 & 21.4 \\
\hline \multicolumn{3}{|l|}{ Health Insurance } \\
\hline Yes & 66 & 94.3 \\
\hline No & 4 & 5.7 \\
\hline \multicolumn{3}{|l|}{ Side of brain lesion } \\
\hline Left & 34 & 48.6 \\
\hline Right & 36 & 51.4 \\
\hline \multicolumn{3}{|l|}{ Lesion type } \\
\hline Infarction & 47 & 67.1 \\
\hline Hemorrhagic & 23 & 32.9 \\
\hline
\end{tabular}

$(\bar{X} \pm S D)=$ mean \pm standard deviation, min= minumum, max = maximum floor effect, was also higher for the SF-36 scale (range, 1.4-30.0\%) than for the domains of WHOQOL-100 scale (range, 1.4-2.9\%).

\section{Reliability}

The two questionnaires exhibit acceptable values with respect to internal consistency $(>0.70)$ with the exception of one scale each. However, the values for these subscales are within an acceptable range (SF-36: PF- Cronbach's alpha $=0.95$, MH-Cronbach's alpha $=0.67$; SF- Cronbach's alpha $=0.88$, WHOQOL100: Physical -Cronbach's alpha $=0.62$, Psychological - Cronbach's alpha=0.72, Relationship-Cronbach's alpha $=0.82$ ). For all but two of the comparable domains, alpha coefficients of the SF-36 were higher than those of the WHOQOL-100. The psychological domain of the WHOQOL-100 had a higher alpha coefficient than the mental health domain of the SF-36 [Table 2].

\section{Validity}

With regard to convergent validity, correlations were found between comparable domains of the two instruments [Table 3]. The physical domain on the WHOQOL-100 correlated moderate to good with the pain and vitality domain of the SF-36; it correlated fair with the physical functioning, role limitations due to physical health problems, general health perception, social functioning and role limitations due to emotional problems domains of the SF-36. The psychological domain on the WHOQOL-100 correlated fair with the physical functioning, role limitations due to physical health problems, pain, social functioning and role limitations due to emotional problems, mental health domains of the SF-36; it correlated moderate to good with the general health perception and vitality domains of the SF-36. Relationship domain on the WHOQOL100 was fair correlated with the physical functioning, general health perception, vitality, social functioning, role limitations due to emotional problems and mental health domains of the SF-36. Overall QOL domain of the WHOQOL-100 correlated particularly moderate to good with the vitality domain of the SF-36, but also moderately with the other domains of the SF-36.

\section{Agreement of specific domains of SF-36 with WHOQOL-100}

The different domains of the SF-36 cannot be automatically transferred to several domains in the WHOQOL-100. However, there are a few domains that intend to describe the same aspect of HRQOL, e.g., physical function (SF-36) and physical health (WHOQOL-100), mental health (SF-36) and psychological (WHOQOL-100), social function (SF-36) and social relationships domain (WHOQOL-100), general health perceptions (SF-36) and general health perceptions (WHOQOL-100). The compliance was evaluated with 


\begin{tabular}{|c|c|c|c|c|c|}
\hline \multicolumn{6}{|c|}{ Table 2: Analysis of subscales of SF-36 and WHOQOL-100 } \\
\hline & $(\bar{X} \pm S D)$ & Median & Floor (\%) & Ceiling (\%) & Cronbach's Alpha \\
\hline \multicolumn{6}{|l|}{ SF 36} \\
\hline Physical Functioning & $50.6 \pm 34.0$ & 57.5 & $0(12.9)$ & $100(4.3)$ & 0.95 \\
\hline Physical Role Limitations & $54.3 \pm 42.6$ & 50.0 & $0(30.0)$ & $100(37.1)$ & 0.88 \\
\hline Pain & $65.0 \pm 32.7$ & 75.0 & $0(1.4)$ & $100(37.1)$ & 0.85 \\
\hline General Health Perceptions & $39.8 \pm 17.1$ & 40.0 & $0(1.4)$ & $80(4.3)$ & 0.62 \\
\hline Vitality & $41.0 \pm 21.2$ & 40.0 & $0(2.9)$ & $90(1.4)$ & 0.64 \\
\hline Social Functioning & $68.9 \pm 30.7$ & 75.0 & $0(5.7)$ & $100(31.4)$ & 0.88 \\
\hline Emotional Role Limitations & $51.4 \pm 40.8$ & 66.7 & $0(1.4)$ & $100(37.1)$ & 0.74 \\
\hline Mental Health & $50.6 \pm 18.7$ & 50.0 & $4(2.9)$ & $84(2.9)$ & 0.67 \\
\hline Physical component summary (PCS) & $40.3 \pm 9.1$ & 39.3 & $18.2(1.4)$ & $56.9(1.4)$ & \\
\hline Mental component summary (MCS) & $40.8 \pm 10.8$ & 40.4 & $15.5(1.4)$ & $62.6(1.4)$ & \\
\hline \multicolumn{6}{|l|}{ WHOQOL-100 } \\
\hline Physical & $13.0 \pm 3.0$ & 12.7 & $6.67(1.4)$ & $19.0(2.9)$ & 0.62 \\
\hline Psychological & $12.4 \pm 2.5$ & 12.8 & $6.80(1.4)$ & $17.40(1.4)$ & 0.72 \\
\hline Independence & $10.9 \pm 2.3$ & 10.4 & $5.50(2.9)$ & $18.0(1.4)$ & 0.77 \\
\hline Relationship & $12.6 \pm 2.6$ & 12.3 & $7.33(1.4)$ & $19.67(1.4)$ & 0.82 \\
\hline Environment & $13.1 \pm 2.2$ & 13.1 & $7.25(1.4)$ & $18.75(1.4)$ & 0.92 \\
\hline Spirituality & $11.3 \pm 3.0$ & 11.0 & $6.0(1.4)$ & $20.0(1.4)$ & 0.82 \\
\hline Overall QoL & $11.29 \pm 2.96$ & 11.0 & $4.0(1.4)$ & $19.0(1.4)$ & 0.80 \\
\hline
\end{tabular}

$\overline{(\bar{X} \pm S D)}=$ mean \pm standard deviation

Table 3: Correlations between SF 36 and WHOQOL-100

\begin{tabular}{|c|c|c|c|c|c|c|c|c|c|c|c|c|c|c|c|c|}
\hline \multirow{3}{*}{$\begin{array}{l}\text { WHOQOL } \\
\text {-100 Domain }\end{array}$} & \multicolumn{16}{|c|}{ SF 36 Domain } \\
\hline & \multicolumn{2}{|c|}{$\begin{array}{l}\text { Physical } \\
\text { Functioning }\end{array}$} & \multicolumn{2}{|c|}{$\begin{array}{c}\text { Physical Role } \\
\text { Limitations }\end{array}$} & \multicolumn{2}{|c|}{ Pain } & \multicolumn{2}{|c|}{$\begin{array}{l}\text { General Health } \\
\text { Perceptions }\end{array}$} & \multicolumn{2}{|c|}{ Vitality } & \multicolumn{2}{|c|}{$\begin{array}{c}\text { Social } \\
\text { Functioning }\end{array}$} & \multicolumn{2}{|c|}{$\begin{array}{c}\text { Emotional Role } \\
\text { Limitations }\end{array}$} & \multicolumn{2}{|c|}{$\begin{array}{l}\text { Mental } \\
\text { Health }\end{array}$} \\
\hline & $r$ & R2 & $r$ & R2 & $r$ & R2 & $r$ & R2 & $r$ & R2 & $r$ & R2 & $r$ & R2 & $r$ & R2 \\
\hline Physical & $\begin{array}{c}r=0.311 \\
p=009\end{array}$ & 0.10 & $\begin{array}{l}r=0.452 \\
p<0.001\end{array}$ & 0.20 & $\begin{array}{l}r=0.606 \\
p<0.001\end{array}$ & 0.37 & $\begin{array}{l}r=0.446 \\
p<0.001\end{array}$ & 0.20 & $\begin{array}{l}r=0.599 \\
p<0.001\end{array}$ & 0.36 & $\begin{array}{l}r=0.370 \\
p=0.002\end{array}$ & 0.14 & $\begin{array}{l}r=0.468 \\
p<0.001\end{array}$ & 0.22 & $\begin{array}{l}r=0.336 \\
p=0.004\end{array}$ & 0.11 \\
\hline $\begin{array}{l}\text { Psych- } \\
\text { ological }\end{array}$ & $\begin{array}{l}r=0.364 \\
p=0.002\end{array}$ & 0.13 & $\begin{array}{l}r=0.413 \\
p<0.001\end{array}$ & 0.17 & $\begin{array}{l}r=0.424 \\
p<0.001\end{array}$ & 0.18 & $\begin{array}{l}r=0.541 \\
p<0.001\end{array}$ & 0.29 & $\begin{array}{l}r=0.534 \\
p<0.001\end{array}$ & 0.29 & $\begin{array}{l}r=0.420 \\
p<0.001\end{array}$ & 0.18 & $\begin{array}{l}r=0.428 \\
p<0.001\end{array}$ & 0.18 & $\begin{array}{l}r=0.462 \\
p<0.001\end{array}$ & 0.21 \\
\hline $\begin{array}{l}\text { Indepen- } \\
\text { dence }\end{array}$ & $\begin{array}{l}r=0.696 \\
p<0.001\end{array}$ & 0.48 & $\begin{array}{l}r=0.289 \\
p=0.015\end{array}$ & 0.08 & $\begin{array}{l}r=0.258 \\
p=0.031\end{array}$ & 0.07 & $\begin{array}{l}r=0.543 \\
p<0.001\end{array}$ & 0.29 & $\begin{array}{l}r=0.532 \\
p<0.001\end{array}$ & 0.28 & $\begin{array}{l}r=0.300 \\
p=0.011\end{array}$ & 0.09 & $\begin{array}{l}r=0.200 \\
p=0.098\end{array}$ & 0.04 & $\begin{array}{l}r=0.288 \\
p=0.016\end{array}$ & 0.08 \\
\hline $\begin{array}{l}\text { Relation- } \\
\text { ship }\end{array}$ & $\begin{array}{l}r=0.391 \\
p=0.001\end{array}$ & 0.15 & $\begin{array}{l}r=0.238 \\
p=0.047\end{array}$ & 0.06 & $\begin{array}{l}r=0.212 \\
p=0.079\end{array}$ & 0.04 & $\begin{array}{l}r=0.331 \\
p=0.005\end{array}$ & 0.11 & $\begin{array}{l}r=0.434 \\
p<0.001\end{array}$ & 0.19 & $\begin{array}{l}r=0.324 \\
p=0.006\end{array}$ & 0.10 & $\begin{array}{l}r=0.238 \\
p=0.033\end{array}$ & 0.06 & $\begin{array}{l}r=0.285 \\
p=0.017\end{array}$ & 0.08 \\
\hline $\begin{array}{l}\text { Environ- } \\
\text { ment }\end{array}$ & $\begin{array}{l}r=0.156 \\
p=0.197\end{array}$ & 0.02 & $\begin{array}{l}r=0.451 \\
p<0.001\end{array}$ & 0.20 & $\begin{array}{l}r=0.245 \\
p=0.041\end{array}$ & 0.06 & $\begin{array}{l}r=0.334 \\
p=0.005\end{array}$ & 0.11 & $\begin{array}{l}r=0.509 \\
p<0.001\end{array}$ & 0.26 & $\begin{array}{l}r=0.377 \\
p=0.001\end{array}$ & 0.14 & $\begin{array}{l}r=0.388 \\
p=0.001\end{array}$ & 0.02 & $\begin{array}{l}r=0.421 \\
p<0.001\end{array}$ & 0.18 \\
\hline Spirituality & $\begin{array}{l}r=0.227 \\
p=0.059\end{array}$ & 0.05 & $\begin{array}{l}r=0.188 \\
p=0.119\end{array}$ & 0.04 & $\begin{array}{l}r=0.238 \\
p=0.047\end{array}$ & 0.06 & $\begin{array}{l}r=0.160 \\
p=0.187\end{array}$ & 0.03 & $\begin{array}{l}r=0.445 \\
p<0.001\end{array}$ & 0.20 & $\begin{array}{l}r=0.369 \\
p=0.002\end{array}$ & 0.14 & $\begin{array}{l}r=0.268 \\
p=0.025\end{array}$ & 0.07 & $\begin{array}{l}r=0.301 \\
p=0.011\end{array}$ & 0.09 \\
\hline $\begin{array}{l}\text { Overall } \\
\text { QoL }\end{array}$ & $\begin{array}{l}r=0.399 \\
p=0.001\end{array}$ & 0.16 & $\begin{array}{l}r=0.315 \\
p=0.008\end{array}$ & 0.10 & $\begin{array}{l}r=0.344 \\
p=0.004\end{array}$ & 0.12 & $\begin{array}{l}r=0.443 \\
p<0.001\end{array}$ & 0.20 & $\begin{array}{l}r=0.586 \\
p<0.001\end{array}$ & 0.34 & $\begin{array}{l}r=0.423 \\
p<0.001\end{array}$ & 0.18 & $\begin{array}{l}r=0.317 \\
p=0.008\end{array}$ & 0.10 & $\begin{array}{l}r=0.407 \\
p<0.001\end{array}$ & 0.17 \\
\hline
\end{tabular}

\#The bold numbers are the correlation coefficients between similar subscales of the two scales

\begin{tabular}{llll}
\hline \multicolumn{4}{c}{ Table 4: Studies using Blant-Altman plots } \\
\hline Sisease & Scales & Results & Authors \\
Rheumatoid arthritis & SF 36 and ROAD* & ROAD subscales were slightly more & Salaffi 2005 (25) \\
& & sensitive to perceived change in & \\
& functional disability than those of & \\
& SF-36 PCS & Scheingraber (26) \\
\hline
\end{tabular}

${ }^{*}$ The Recent-Onset Arthritis Disability Index **The gastrointestinal quality of life index

Bland Altman plots [Figure 1]. Limits of agreement in similar domains of the two instruments were very large. In all four demonstrated Bland Altman plots, there was agreement of the scales in the measurements of similar fields of quality of life.

\section{Discussion}

\section{Quality of life}

The SF-36 and the WHOQOL-100 questionnaires have a different background, structure, content, and length. Nonetheless, a close relationship between the domains that assessed physical function, social functioning, bodily pain, and overall health-related QOL was observed.

This study demonstrated that in the evaluation of stroke patients' QOL, the independence level and general health perception in the WHOQOL scale, and validity and general health perception in the SF-36 scale were the most affected fields. The deterioration in 

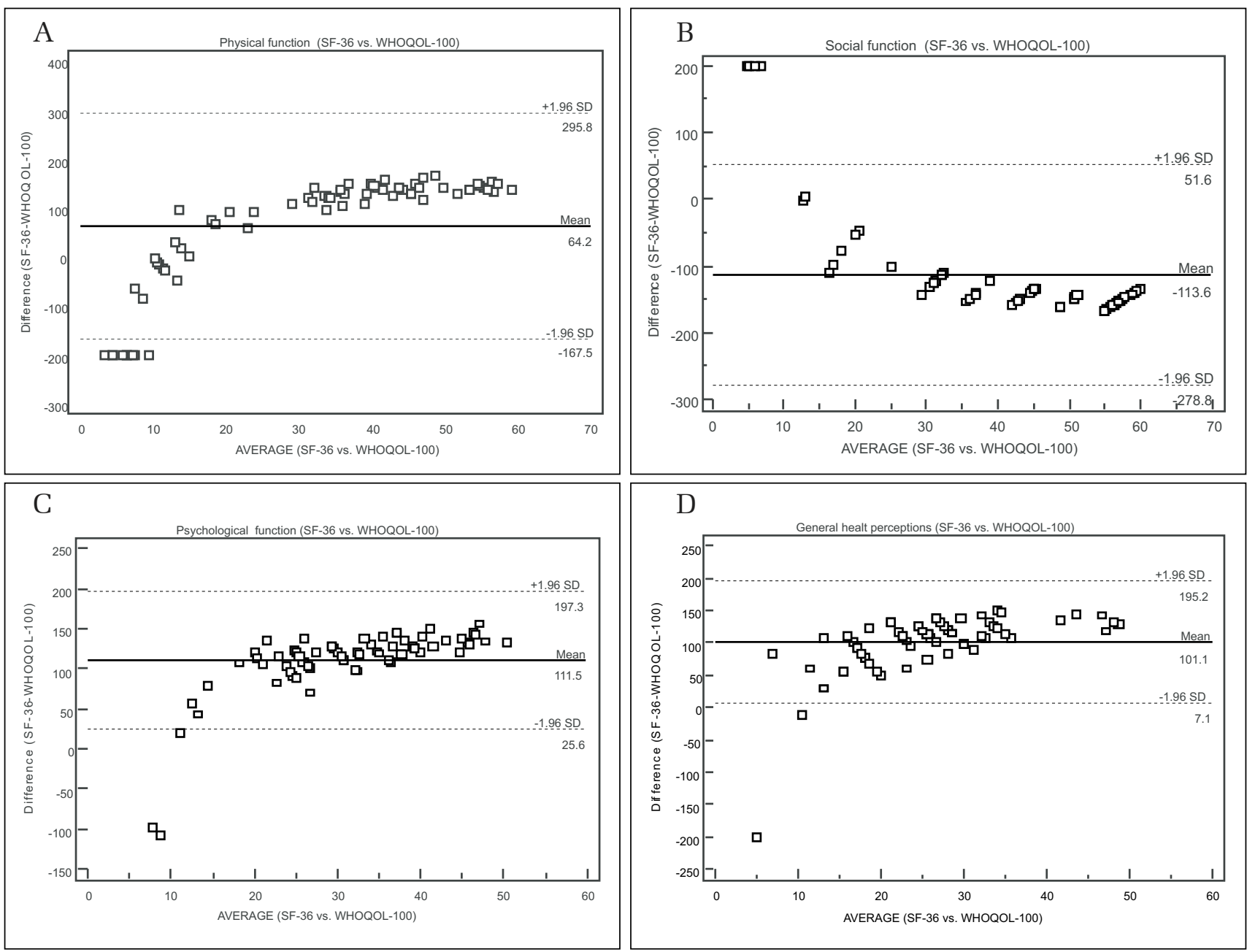

Figure 1A- D: Bland Altman plots for four different subgroups according to specific domains: left upper quadrant: physical functioning (SF-36) and physical Health (WHO QOL-100). Right upper quadrant: Social functioning (SF-36) and social relationships domains (WHO QOL-100). Left lower quadrant mental health (SF-36) and psychological domain (WHO QOL-100). Right upper quadrant: general health perceptions (SF-36) and overall QOL and general health perceptions (WHO QOL-100).The differences between the SF-36 and WHOQ OL-100 values are drawn, according to the average of two methods (SF-36WHOQOL-100)/2. The dotted lines mark the upper and lower limits of the $95 \%$ confidence interval (mean +2 SD) and dashed line indicate the bias. The difference between the SF and WHOQ OL-100 values are drawn, according to the average of the two methods (SF-36WHOQOL100)/2. The dotted lines mark the upper and lower limits of the $95 \%$ confidence interval (mean +2 SD) and the dashed line indicate the bias.

these fields may be due to disability caused by stroke. This study also showed that stroke has a negative effect on the QOL, which is compliant with the findings of similar studies. ${ }^{[18,19]}$ This is an expected result when the physical and mental deterioration stroke causes are considered.

A generic QOL instrument, designed for a variety of populations and measuring a comprehensive set of health concepts, is likely to have problems with the ceiling and floor effect. It is widely accepted that the more homogeneous the distribution of scores, the lower the floor and ceiling effects, the better the measuring instruments. ${ }^{[10]}$ The SF-36 has been shown to be susceptible to ceiling and floor effects, and it has been suggested that ceiling and floor effects are over-expected in generic HRQL instruments, simply because they aim to be applicable to a wide range of populations. ${ }^{[20]}$ The findings of the present study were consistent with the literature in that they demonstrated a large ceiling and floor effect in the SF-36 measurements of stroke patients. ${ }^{[21]}$ There is no study in the literature where WHOQOL-100 is used only for stroke patients and psychometric analysis were made. In addition, the present study determined the ceiling and floor effect of the WHOQOL-100 in stroke patients.

\section{Reliability}

The WHOQOL-100 and SF-36 had acceptable consistency within the facets and their domains in the sample population of this study. The internal consistencies of the subscales showed satisfactory values. However, for three subscales in each instrument the value fell below 0.70: subscales GH, VT and $\mathrm{MH}$ of the SF-36, and the WHOQOL-100 physical domain. According to Young et al., ${ }^{[9]}$ the WHOQOL-100 found (alpha)-values ranging from 0.76-0.90. In the present 
study the mean Cronbach's alpha was a little lower for the WHOQOL-100 than for the SF-36 in stroke patients. These findings suggest that it is not only the magnitude of the correlation among items, but also the number of items in the scale that affects the internal consistency.

\section{Validity}

A moderate relationship between the domains that assessed physical, psychological, relationship and overall QOL of the similar fields of the two instruments was observed. However, mental subscales of the SF-36 correlated equally with both physical and psychological WHOQOL-100. The results suggest that the two instruments are generally sampling similar areas of health. Bonimi et al., found a moderate relationship between the SF-36 and WHOQOL-Bref in similar fields in a study performed in a general population. ${ }^{[22]}$ Skewington et al., reported that physical subscales of the SF-36 were more strongly correlated with physical than the psychological subscales of the WHOQOL-100 in patients with chronic pain. ${ }^{[23]}$ The WHOQOL-100 scale proved to be a reliable and valid instrument for assessing the QOL of patients with stroke in the present study, which is compliant with the findings of similar studies. ${ }^{[9]}$

\section{Agreement of specific domains of SF-36 with WHOQOL-100}

Bland-Altman plot has become a popular tool for the presentation of method-comparison studies. ${ }^{[24]}$ In the present study, there was agreement of the scales in the measurements of similar fields of QOL in all four demonstrated Bland-Altman plots. Limits of agreement in similar domains of the two instruments were very large. Horizontal lines were drawn at the mean difference, and at the mean difference \pm 1.96 times the standard deviation of the differences. If the differences within the mean $\pm 1.96 \mathrm{SD}$ are not clinically important, the two methods may be used interchangeably.

Although there are studies reporting the QOL in stroke patients three months or more after the onset of stroke, this study includes patients who had stroke for six months or more.

\section{Strengths and limitations of the study}

Although the QOL has been evaluated in patients with stroke in many studies by SF-36 QOL scale, this is the first study in the literature where the WHOQOL-100 has been used to assess the QOL of stroke patients. ${ }^{[9]}$

There are only two studies in the literature comparing the SF-36 QOL and other QOL scales by using BlandAltman plots. ${ }^{[25,26]}$ In the present study, in addition to correlation analysis, the WHOQOL-100 was compared with the SF-36 by using Bland-Altman scales for the first time. The findings of this study have demonstrated the agreement of similar fields of these two QOL scales.

\section{Implications}

The present study demonstrated that SF-36 and WHOQOL-100 QOL scales are both useful in the practical evaluation of patients with stroke. The results suggest that the two instruments are generally sampling similar areas of health. This finding supports the notion that there are several key dimensions that constitute health-related QOL, as well as providing further support for the construct validity of the assessments of these domains with either instrument. The use of WHOQOL-100 scale may be considered as an alternative instrument in the QOL assessment of patients with stroke. The healthcare practitioner should consider the patient's stage of disease and treatment goals, when selecting a HRQOL tool for the stroke patient.

\section{Acknowledgment}

Authors have no financial or proprietary interest in any instrument or products used in this study.

\section{References}

1. Hackett ML, Duncan JR, Anderson CS, Broad JB, Bonita R. Healthrelated Quality of life among long-term survivors of stroke: Results from the Auckland Stroke Study, 1991-1992. Stroke 2000;31:440-7.

2. Garraway WM, Whismann JP, Furlan AI, Phillips LH, Kurland LT, O'Fallon WM. The declining incidence of stroke. N Engl J Med 1979;300:449-52.

3. Sturm JW, Osborne RH, Dewey HM, Donnan GA, Macdonell RA, Thrift AG. Brief comprehensive quality of life assessment after stroke: The assessment of quality of life instrument in the north East melbourne stroke incidence study (NEMESIS). Stroke 2002;33:2888-94.

4. Yamakawa Y, Satoh S, Sawa S, Ohta H, Asada T. Efficacy of milnacipran on poststroke depression on inpatient rehabilitation. Psychiatry Clin Neurosci 2005;59:705-10.

5. Hobart JC, Williams LS, Moran K, Thompson AJ. Quality of life measurement after stroke: uses and abuses of the SF-36. Stroke 2002;33:1348.

6. Anderson C, Laubscher S, Burns R. Validation of the Short Form 36(SF-36) health survey questionnaire among stroke patients. Stroke 1996;27:1812-6.

7. Dorman PJ, Dennis M, Sandercock P. How do scores on the EuroQol relate to scores on the SF-36 after stroke? Stroke 1999;30:2146-51.

8. Mahony PG, Rodgers H, Thomson RG, Dobson R, James OF. Is the SF-36 suitable for assessing health status of older stroke patients? Age Ageing 1998;27:19-22.

9. Li L, Young D, Xiao S, Zhou X, Zhou L. Psychometric properties of the WHO Quality of Life questionnaire (WHOQOL-100) in patients with chronic diseases and their caregivers in China. Bull World Health Organ 2004;82:493-502.

10. Ware JE Jr. SF-36 Health survey update. Spine 2000;25:3130-9.

11. Ware JE Jr, Sherbourne CD. The MOS 36 item short-form health survey (SF-36). Med Care 1992;30:473-83.

12. Ware JE Jr, Kosinski M, Keller SD. SF-36 Physical and Mental Health Summary Scales: A users manual. 5th ed. Boston, MA: The Health Institute, New England Medical Centre; 1994.

13. Pinar R. Reliability and construct validity of the SF-36 in Turkish cancer patients. Qual Life Res 2005;14:259-64.

14. Skevington SM. Advancing cross-cultural research on quality of life: Observations drawn from the WHOQOL development. Qual Life Res 
2002;11:135-44.

15. Power M, Harper A, Bullinger M. The World Health Organization WHOQOL-100: Tests of the universality of Quality of Life in 15 different cultural groups worldwide. Health Psychol 1999;18:495-505.

16. Skevington SM. Measuring quality of life in Britain: Introducing the WHOQOL-100. J Psychosom Res 1999;47:449-59.

17. Portney LG, Watkins, MP. Foundations of clinical research: Applications to practice. 2nd ed. Upper Saddle River, NJ: Prentice-Hall; 2000. p. 482-629.

18. Li TC, Lee YD, Lin CC, Amidon RL. Quality of life primary caregivers of elderly with cerebrovasculer disease or diabetes hospitalized for acute care: Assessment of well-being and functioning using the SF-36 health questionnaire. Qual Life Res 2004;13:1081-8.

19. Kong KH, Yang SY. Health-related quality of life among chronic stroke survivors attending a rehabilitation clinic. Singapore Med J $2006 ; 47: 213-8$

20. Wann-Hansson C, Hallberg IR, Risberg B, Klevsgård R. Comparison of the Notthingham Health Profile and Short form 36 Health Survey in patients with chronic lower limb ischaemia in a longitudinal perspective. Health Qual Life Outcomes 2004;2:9.

21. Pickard AS, Johnson JA, Feeny DH. Responsiveness of generic healthrelated qualty of life measures in stroke. Qual Life Res 2005;14:207-19.
22. Bonomi AE, Patrick DL, Bushnell DM, Martin M. Validation of the United States'version of the World Health Organization Quality of Life (WHOQOL) instrument. J Clin Epidemiol 2000;53:1-12.

23. Skevington SM, Carse MS, Williams AC. Validation of the WHOQOL100: Pain management improves quality of life for chronic pain patients. Clin J Pain 2001;17:264-75.

24. Mantha S, Roizen MF, Fleisher LA, Thisted R, Foss J. Comparing methods of clinical measurement: Reporting standards for Bland and Altman analysis. Anesth Analg 2000;90:593-602.

25. Salaffi F, Stancati A, Neri R, Grassi W, Bombardieri S. Measuring functional disability in early rheumatoid arthritis: The validity, reliability and responsiveness of the Recent-Onset Arthritis Disability (ROAD) index. Clin Exp Rheumatol 2005:S31-42.

26. Scheingraber S, Scheingraber T, Brauckhoff M, Dralle H. Comparison between a general and a disease-specific health-related quality-of life questionnaire in patients after pancreatic surgery. J Hepatobiliary Pancreat Surg 2005;12:290-7.

Accepted on 07-11-08

Source of Support: Nil, Conflict of Interest: None declared. 